\title{
An ultra low-power off-line APDM-based switchmode power supply with very high conversion efficiency
}

Nielsen, Nils

Published in:

Proceedings on IEEE Applied Power Electronics Conference and Exposition

Link to article, DOI:

10.1109/APEC.2001.911631

Publication date:

2001

Document Version

Publisher's PDF, also known as Version of record

Link back to DTU Orbit

Citation (APA):

Nielsen, N. (2001). An ultra low-power off-line APDM-based switchmode power supply with very high conversion efficiency. In Proceedings on IEEE Applied Power Electronics Conference and Exposition (Vol. 1, pp. 81-87) https://doi.org/10.1109/APEC.2001.911631

\section{General rights}

Copyright and moral rights for the publications made accessible in the public portal are retained by the authors and/or other copyright owners and it is a condition of accessing publications that users recognise and abide by the legal requirements associated with these rights.

- Users may download and print one copy of any publication from the public portal for the purpose of private study or research.

- You may not further distribute the material or use it for any profit-making activity or commercial gain

- You may freely distribute the URL identifying the publication in the public portal 


\title{
An ultra low-power off-line APDM-based switchmode power supply with very high conversion efficiency
}

\author{
Nils Nielsen \\ Department for Applied Electronics, IAE \\ Technical University of Denmark, DTU \\ Buildning 451, DK-2800 Lyngby, Denmark
}

\begin{abstract}
This article describes the results from the research work on design of a ultra low power off-line power supply with very high conversion efficiency. The input voltage is $230 \mathrm{VAC}$ nominal and output voltage is $5 \mathrm{VDC}$. With ultra low power levels is meant, a output power level in the area ranging from $50 \mathrm{~mW}$ and up to $1000 \mathrm{~mW}$. The small power supply is intended for use as a standby power supply in mains operated equipment, which requires a small amount of power in standby mode.
\end{abstract}

\section{INTRODUCTION}

This article describes the final design and results from a Ph.D. project [1] at the Technical University of Denmark, DTU [2].

The motive for this work, with small and highly loss optimized power supply has its origin in a cooperative project between The Technical University of Denmark, the Danish Energy Agency [3] and three Danish electronics equipment manufacturers [4]. The purpose of this project was to investigate the leaking electricity issue and how to lower leaking electricity in common electrical equipment by using a separate high efficiency switch mode converter.

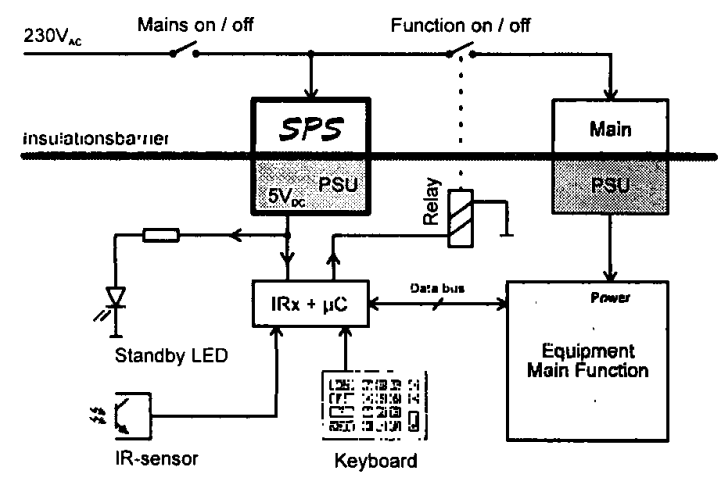

Figure 1 Intended use of the standby module
This article covers only the standby power supply shown as the SPS-block in Figure 1. Leaking electricity losses is also called standby power losses.

At the start of the standby power project the specifications for the small ultra low power standby power supply was defined as:

Target specification for the new low loss SPS-unit:

- Input voltage:

$$
\begin{aligned}
& 230 V_{A C}\left(195-265 V_{A C}\right) \\
& \text { or } \\
& 115 V_{A C} \text { and } 230 V_{A C}\left(85 V_{A C}-265 V_{A C}\right)
\end{aligned}
$$

- Output voltage:

$U_{\text {out }} 5 \mathrm{VDC}$

- Output Power:
Min. load
Max. load
$50 \mathrm{~mW}$
$1000 \mathrm{~mW}$

- Efficiency:

At least 65\%@50mW

At least 80\%@1000mW

- Galvanic insulation due to: Norm

- Operating temperature: $0-70^{\circ} \mathrm{C}$

- Volume less than or equal to: $10 \mathrm{~cm}^{3}$

- Robust:

(Electrical design, Manufacture, Technology)

The overall design should furthermore be carried out in a way so it both facilitates an easy construction by common of-the-shelf components and a later ICdesign of the control circuit. 


\section{Discussion}

One of the major problems in the design of power supplies for ultra low power is to keep the idle losses (constant losses) low in the power converters own internal circuit. Secondly the losses which is a function of the load current (variable losses) should depend in a reasonable way.

In order to get ahead the priority list for most important properties is defined as shown in the list below. The order in the list might suprise the reader, because the cost issue is the last item. But in order to ensure the fundemental research work it is put in as the last item, but of course there is close attention to this subject throughout the whole design work. Later, when a proper solution is found one can determine whether or not the final solution is useable and then make some trade off's (most likely on efficiency) to lower the costs.

\section{Priority of design properties - in descending order:}

Efficiency, Robustness, Facilitate later IC realization of the control circuit section, Facilitate a later mass produced module design, Components is common standard types with second sources, No or few exotic components, Smallest possible physical volume, Lowest possible cost.

If we for short a time take a look at the specification goals, it can be seen that the maximum total losses in the whole converter at full load $(1000 \mathrm{~mW})$ can be $250 \mathrm{~mW}$ but at the minimum load it can only be $27 \mathrm{~mW}$ ! And this is something special, because the $27 \mathrm{~mW}$ is the sum of the raw conversion losses and the idle loss in the control circuit. If we assume that load dependent losses are purely proportional with the load current. How much energy is then left for use in the control circuit if the efficiency specification should be satisfied?.

$$
\eta\left(I_{\text {out }}\right)=\frac{U_{\text {out }} \cdot I_{\text {out }}}{U_{\text {out }} \cdot I_{\text {out }}+k_{2} \cdot I_{\text {out }}+k_{1}}
$$

When the constants $k_{1}$ and $k_{2}$ are determined the following final formula is given:

$$
\eta\left(I_{\text {out }}\right)=\frac{U_{\text {out }} \cdot I_{\text {out }}}{U_{\text {out }} \cdot I_{\text {out }}+1.174 \cdot \frac{W}{A} \cdot I_{\text {out }}+15.18 m W}
$$

This shows what is left to the control circuit - only $15.18 \mathrm{~mW}$. Compared to an ordinary $6.2 \mathrm{~V}$ zenerdiode which consumes about $6.2 \mathrm{~V} \times 5 \mathrm{~mA}=31 \mathrm{~mW}$.

Figure 2 shows the efficiency for a good linear power supply using a loss optimized conventional mains transformer, which is compared to the calculated target efficiency given by formula (2). More efficiency comparisons for conventional topologies can be found in $[5,6,7,8]$

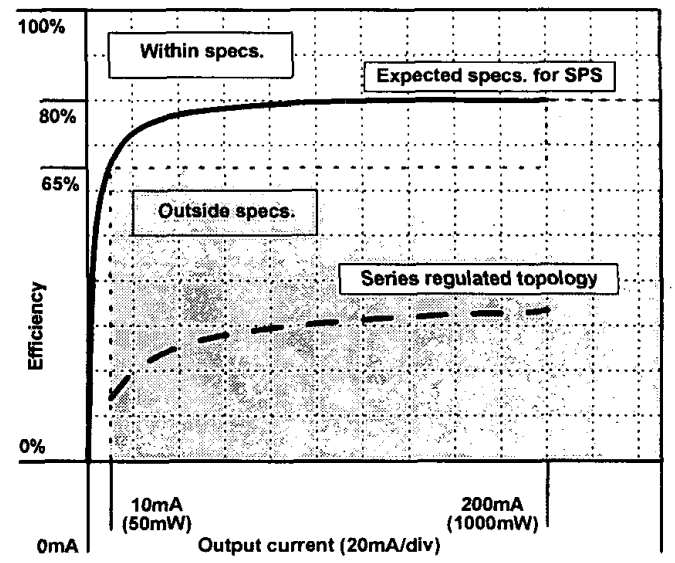

Figure 2 Efficiency comparison

\section{ANALYSIS}

Due to the special attention on high efficiency at very light load levels it is obviously that the control circuit should be designed and chosen in a way which uses low loss design techniques at the outmost extent in any of its circuit parts. It is also desirable that the overall control circuit in the power supply is kept as simple as possible because of the issues on price and reliability.

\section{What conversion topology to use?}

As the result of a topology investigation [5], which was made as part of the project, It was concluded that a one-transistor flyback based topology was the most suitable for the converter. The dominant reasons for selecting this topology is found in its simplicity and because it does not require any high side driver for the switch element. Furthermore it is a well proven topology which is very robust when designed carefully.

\section{What conversion principle to use?}

The next issue is to investigate the possibilities to improve efficiency enough to at least satisfy the expected specifications. If these efficiency levels is compared to obtained efficiency levels in flyback converters which are designed for higher power levels it should be possible to achieve efficiencies above $80 \%$. But it is also known that the issue concerning idle losses is very critical because of the extreme low power level. 
The most dominant losses in a flyback converter design for higher power levels using a constant and high switching frequency are:

At full load the most dominant losses usually are:

1. Conduction losses in flyback diode (V)

2. Parasitic cap. in the high voltage circuit $(C)$

3. Leakage inductance in transformer $(V)$

4. Core and copper losses (V)

At light load the dominant losses usually are:

1. Parasitic cap. in the high voltage circuit (C)

2. Control circuit (primary side) (C)

3. Reference circuit (secondary side) (C)

4. Leakage current in flyback diode (C)

(C) means constant loss and (V) means variable loss.

How to avoid or reduce constant losses:

If the disturbing losses cannot be completely eliminated, then what can be done? A way is to lower the losses to a absolute minimum by changing some or all the constant losses into variable losses.

Variable losses means losses which are proportional to the output power.

If this load/loss dependency can be implemented successfully in a low power flyback converter it is possible to keep the efficiency high over a very wide load range. With the use of this scheme the efficiency is only limited by the raw conversion efficiency, which in this low power case mainly is determined by the loss caused by threshold voltage in the flyback diode.
Eventually when the load gets very low and the internal idle losses are becoming comparable to the load, the efficiency will drop quickly.

The solution for better overall efficiency:

In the usual constant frequency and variable dutycycle flyback design, the duty-cycle is regulated to maintain the correct energy transfer from primary to secondary and thereby keeping the output voltage constant. In this case a switch cycle is composed of a switch-on time $\left(t_{1}\right)$ and switch-off time ( $\left.t_{2}\right)$. If the converter is running in discontinuous conduction mode (DCM) t 2 itself is composed of freewheeling time $\left(t_{2 f}\right)$ and a dead time $\left(\mathrm{t}_{2 \mathrm{r}}\right)$.

Another way to maintain the correct energy transfer is to keep the on-time $t_{1}$ constant thereby transferring a constant energy package per switch cycle. In this case the converter can be designed to show the optimal efficiency in this well defined working point. When this constant energy package transfer scheme is used the energy transfer must be controlled in another way, because the on-time is kept constant. In the new proposed control principle, energy transfer is controlled by regulating the overall density of the transferred energy packages. The desired energy density can either be maintained by a repeated fixed size burst of energy packet or the frequency of single energy packages can be regulated. The first operating mode is called burst mode and the second one is the proposed Analog Pulse Density Modulation (APDM) [9].

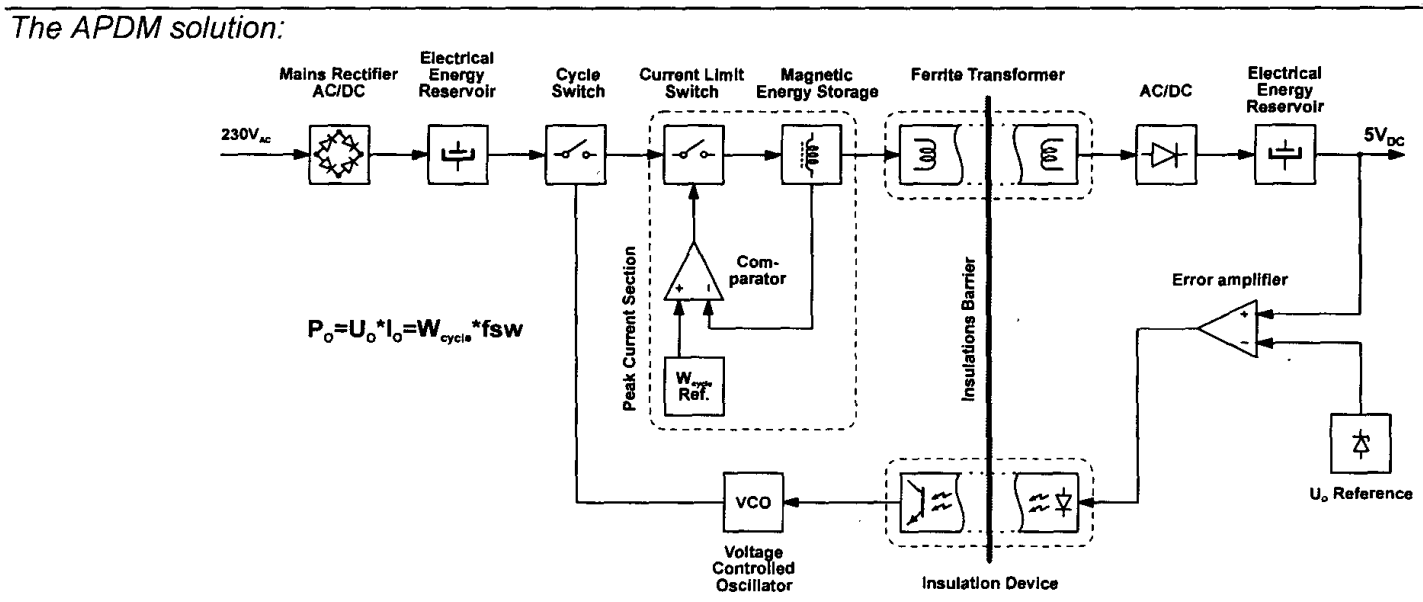

Figure 3 Overall block diagram for the APDM-based standby power supply 
Because of the poor secondary ripple performance of burst mode the APDM principle is used to design the described standby power supply.

By using the APDM principle the most dominant constant loss, which is caused by the parasitic capacitance in the high voltage circuit, is now changed into variable losses.

It can be said, that the APDM based converter operates a short period at full power, where it achieves its best conversion efficiency. In the short full power period the output capacitor is charged. In the dead time the output capacitor delivers the energy to the load.

A noticeable feature of the APDM principle is that the output capacitor does not require any excess capacitance compared to a equal constant switching frequency converter.

If the APDM based converter is used in a environment where it sees relative large and fast step loads, extra capacitance might be needed to give the regulation circuit enough time to find it's new equilibrium.

To optimize the efficiency of the APDM-based converter further, the control circuit must be loss optimized to its outmost extent and especially its reference section which is also active in the dead time period.

To make the APDM-based converter even better a peak current detector is included. With this inclusion the energy packet size is maintained constant even when the input voltage is varying. The advantage is that a very large ripple can be locally compensated and thereby not disturbing the output voltage control loop. Furthermore this quality can be used as a way to reduce the primary link capacitor value or/and extend the power supply input voltage range.

The APDM design allows the supply voltage for the peak-current-detector circuit can be connected to the gate drive voltage, which means that the peakcurrent-detector is only active in the switch on time and thereby reducing the losses.

Figure 4 shows the basic principle of the APDM control circuit. The VCO (Voltage Controlled Oscillator) controls energy transfer and the peak current detector ensures that a constant sized energy packages is transferred on each switch cycle even if the input voltage is not constant.

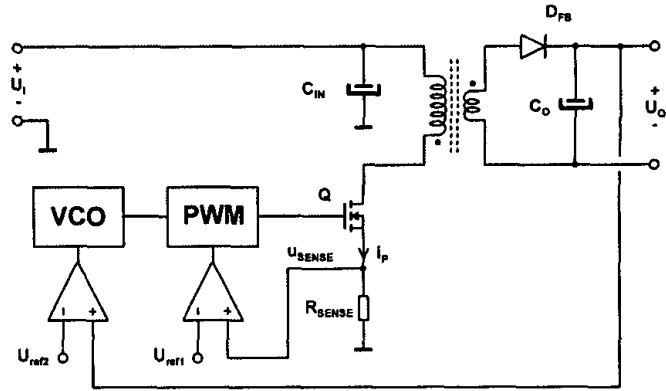

Figure 4 APDM control principle

How is the APDM design optimized?:

The method for designing a high efficiency power supply differs from the usual way to carry out such a design because of the expected low loss levels. In a ordinary design one will typically select a core size which is just big enough to transfer the energy whitout overheating the windings and core material.

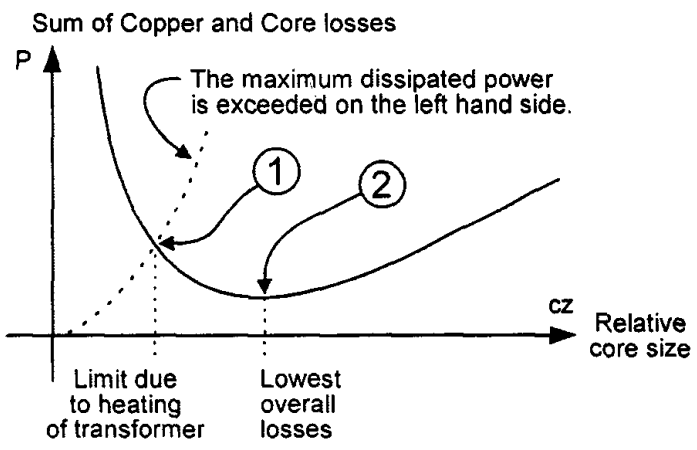

Figure 5 Rough comparison of optimization methods

In this project high temperatures is a word one do not want to hear about, because it also means excessive losses when it is compared to the desired efficiency specifications.

Figure 5 illustrates, how a usual core size optimized design differs from the low loss optimized design.

The curve shows losses as a function of relative core size at a constant amplitude of the flux density (B).

At the point marked ' 1 ' the core size is squeezed down to a minimum where losses causes the highest allowable temperature rise. The other point marked ' 2 ' is where the lowest losses is obtained. 
Then, how can this power supply be designed when maximum allowable dissipation can not be used as a guide for the design? We have to find a function which calculates the overall loss figure for the whole converter in a given working point. In this way of design there are not any well defined parameters which can be used to perform an exact calculation in one step. There are many parameters and component data which all affects the overall losses.

To get further ahead it is necessary to select some parameters and component data and then optimize on the rest to find the best combination among them. Formula 3 shows the basic function which is used to seek out the combination for the best efficiency.

$$
\eta(\overrightarrow{\mathbf{v}})=\eta\left(U_{\text {in }}, I_{o}, U_{\text {refl }}, t_{o n}, C z, S w_{\text {cycles_sec }}, B_{\text {max }}\right)
$$

\section{Description of parameters:}

$\begin{array}{ll}U_{\text {in }} & =\text { Mains input voltage } \\ \text { lo }_{U_{\text {refl }}} & =\text { Output current } \\ \text { ton } & =\text { Reflected voltage on primary side } \\ C Z & =\text { On time at lowest input voltage } \\ S_{\text {cycles_sec }} & =\text { Relative core size } \\ B_{\max } & =\text { Req. energy packages per sec. } \\ & =\text { Max. flux density in core }\end{array}$

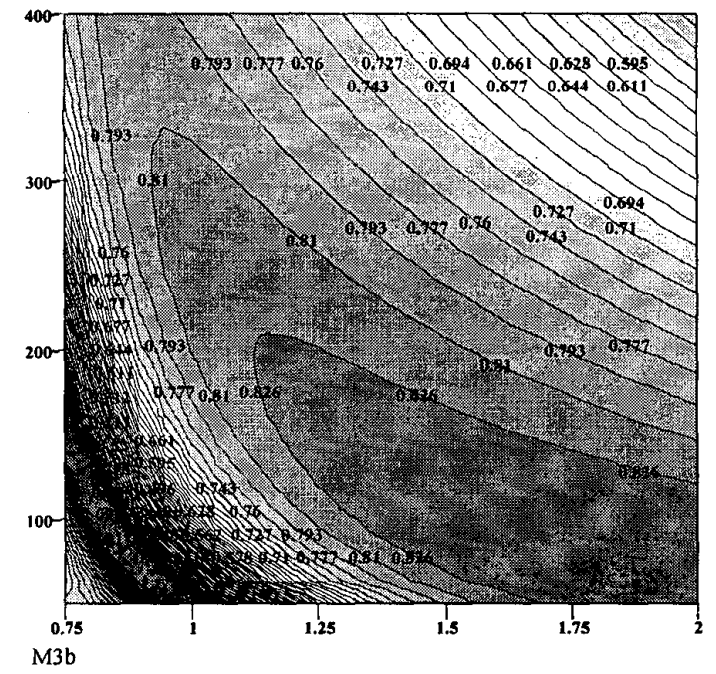

Figure 6 Efficiency as a function of relative core size $c z$ and $B_{\max }$ $\eta\left(230 \mathrm{~V}, 200 \mathrm{~mA}, 122 \mathrm{~V}, 18 \mu \mathrm{s}, \mathrm{cyx}, 20 \mathrm{kHz}, B_{\max } y\right)$

Formula 4 describes the simulated situation A efficiency simulation example is shown in figure 6 .
All the calculated data applies to a design with a $\mathrm{E} 16 / 8 / 5$, N87 core and a minimum input AC-voltage of $195 V_{A C}$ and nominal voltage at $230 V_{A C}, B_{\max }$ is $250 \mathrm{mT}$ and the voltage reflected at the primary winding is $122 \mathrm{~V}$ when the flyback diode is conducting.

\section{Calculated energy budget:}

\begin{tabular}{|c|c|c|c|c|c|c|}
\hline Circult part & \multicolumn{2}{|c|}{$I_{0}=50 \mathrm{~mW}$} & \multicolumn{2}{|c|}{$\mathrm{l}_{0}=250 \mathrm{~mW}$} & \multicolumn{2}{|c|}{$l_{0}=1000 \mathrm{~mW}$} \\
\hline & $\mu w$ & $\%$ & $\mu w$ & $\%$ & $\mu w$ & $\%$ \\
\hline & & & & & & \\
\hline Mains rect. & 0 & 0.00 & 0 & 0.00 & 0 & 0.00 \\
\hline LInk capacitor & 24 & 0.14 & 109 & 0.19 & 430 & 0.10 \\
\hline MOS-FET - $t$-on & 0 & 0.00 & 0 & 0.00 & 0 & 0.00 \\
\hline MOS-FET - cond. & 176 & 1.04 & 821 & 1.43 & 3229 & 1.54 \\
\hline MOS-FET - t-off & 460 & 2.73 & 2107 & 3.66 & 8284 & 3.95 \\
\hline MOS-FET - Cds & 982 & 5.83 & 4501 & 7.81 & 17696 & 8.43 \\
\hline MOS-FET - Cgs & 139 & 0.82 & 637 & 1.11 & 2503 & 1.19 \\
\hline Current sense & 98 & 0.58 & 447 & 0.78 & 1759 & 0.84 \\
\hline Cu Primary & 124 & 7.36 & 567 & 0.98 & 2229 & 1.06 \\
\hline Cu Secondary & 796 & 4.72 & 3647 & 6.33 & 14338 & 6.83 \\
\hline Core loss & 1803 & 10.70 & 8261 & 14.34 & 32476 & 15.47 \\
\hline $\begin{array}{l}\text { Leakage } \\
\text { inductance }\end{array}$ & 936 & 5.55 & 4290 & 7.45 & 16867 & 8.03 \\
\hline $\begin{array}{l}\text { Parasitic cap. in } \\
\text { coil }\end{array}$ & 1654 & 9.81 & 7578 & 13.15 & 29793 & 14.19 \\
\hline $\begin{array}{l}\text { Control circuit - } \\
\text { primary }\end{array}$ & 3289 & 19.52 & 3295 & 5.72 & 3315 & 1.58 \\
\hline $\begin{array}{l}\text { Control circuit - } \\
\text { secondary }\end{array}$ & 2139 & 12.69 & 2139 & 3.71 & 2139 & 1.02 \\
\hline Aux-rectifier & 332 & 1.97 & 246 & 4.27 & 228 & 0.11 \\
\hline $\begin{array}{l}\text { Flybackdiode - } \\
\text { Conduction }\end{array}$ & 3414 & 20.26 & 16939 & 29.40 & 67655 & 32.22 \\
\hline $\begin{array}{l}\text { Flyback diodo - } \\
\text { leakage current }\end{array}$ & 43 & 2.55 & 48 & 0.08 & 64 & 0.03 \\
\hline Output Capacitor & 443 & 2.63 & 1977 & 3.43 & 6957 & 3.31 \\
\hline & & & & & & \\
\hline Total Losses & 16852 & 25.21 & 57609 & 18.73 & 209963 & 17.35 \\
\hline Output Power & 50000 & 74.79 & 250000 & 81.27 & 1000000 & 82.65 \\
\hline Input Power & 66852 & 100.00 & 307609 & 100.00 & 1209963 & 100.00 \\
\hline
\end{tabular}

Table 1 Calculated energy budget

The simulation program is intended to show how the efficiency is affected under various operating situations and component selections - before the design of a actual physical circuit.

Table 1 shows the calculated losses in selected component and the overall efficiency. The calculation is shown for the lowest load at $50 \mathrm{~mW}$, at midrange load at $250 \mathrm{~mW}$ and at full load at $1000 \mathrm{~mW}$. 


\section{Experimental results}

Input ripple rejection:

In this design case the standby power supply is designed to compensate out a $200 \mathrm{Vpp}$ primary ripple voltage.

Figure 7 shows a $190.6 \mathrm{Vpp} 100 \mathrm{~Hz}$ ripple voltage across the small (267nF@oV) ceramic link capacitor.

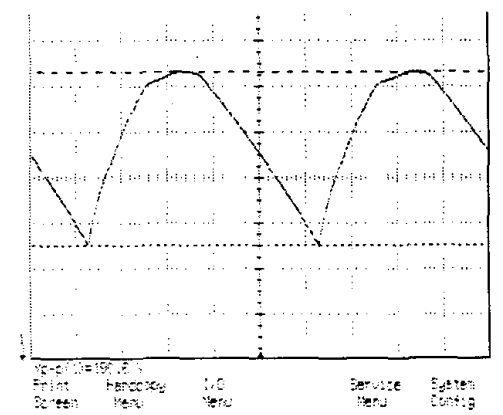

Figure 7 Ripple voltage on link capacitor at lo $=200 \mathrm{~mA}$

Figure 8 shows the resulting $16.25 \mathrm{mVpp} 100 \mathrm{~Hz}$ ripple voltage on the $5 \mathrm{~V}-\mathrm{DC}$ output voltage.

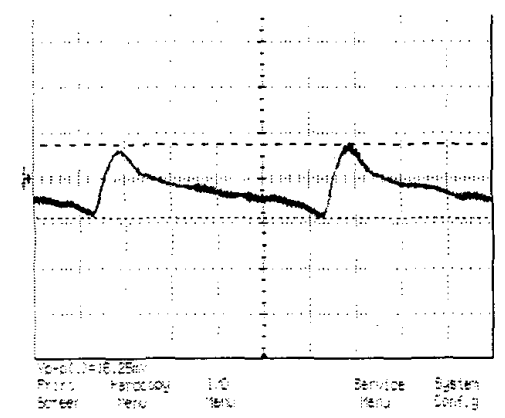

Figure 8 Output ripple voltage at Uin $=230 \mathrm{VAC}$ and $10=200 \mathrm{~mA}$

The efficiency cost for this extreme ability to compensate for a very large ripple voltage is around two percent. As a desired side effect it is very easy to widen the input voltage range to e.g. $85 V_{A C}-265 V_{A C}$ This range enhancement is done simply by adding a $4.7 \mu \mathrm{F} / 385 \mathrm{~V}$ electrolytic capacitor in parallel with the present ceramic link capacitor.

Table 2 shows the measured efficiency for the final APDM based converter when a constant $320 \mathrm{VDC}$ is applied as input voltage. The reason for applying a $D C$ voltage when measuring efficiency is the fact of the extreme low power levels. As it can be seen the converter only consumes approximately $16 \mu \mathrm{A}$ when it runs without any load. (a common multimeter consumes $32 \mu \mathrm{A}$ because of its input resistance of 10Mohm)

\begin{tabular}{|c|c|c|c|c|c|c|c|c|}
\hline $\mathrm{U}_{\mathrm{O}}$ & $\begin{array}{l}\mathrm{I}_{0} \\
\mathrm{~mA}\end{array}$ & $\begin{array}{l}P_{0} \\
\mathrm{~mW}\end{array}$ & $\begin{array}{c}U_{\text {IN }} \\
\mathrm{V}\end{array}$ & $\mathrm{I}_{\mathrm{NA}}$ & $\begin{array}{l}P_{i N} \\
m W\end{array}$ & $\begin{array}{l}\text { Ploss } \\
\mathrm{mW}\end{array}$ & $\begin{array}{l}\text { Cycl/ } \\
\text { sec. }\end{array}$ & $\begin{array}{l}\eta \\
\%\end{array}$ \\
\hline & & & & & & & & \\
\hline 5,069 & 0,000 & 0,00 & 320,40 & 0162 & 5,19 & 5,19 & 0,080 & \\
\hline 5,069 & 1,072 & 5,43 & 20,40 & & 11,76 & 6,33 & 0,160 & 46,20 \\
\hline & & 11,62 & & & & & 0,260 & 80,05 \\
\hline & & 57 & & & & 9,81 & 0,500 & 72,28 \\
\hline & 7,3 & 7,51 & & & 9.47 & 1,96 & 0,671 & 75,82 \\
\hline 5,069 & 10,617 & 3,82 & & & 3,08 & 15,26 & 0,943 & 77,91 \\
\hline 5,069 & 22,570 & 114,41 & 320,40 & 0,4370 & 140.01 & 25,61 & 1,894 & 81,71 \\
\hline 5,069 & 48,542 & 246,06 & & 0,9205 & 294,93 & 48,87 & 4,065 & 83,43 \\
\hline & 71,249 & & & & & 9.14 & 5,917 & 83,93 \\
\hline & 96,259 & 7.94 & & & 8,64 & 90,71 & 7,937 & 84,32 \\
\hline 5,069 & 156,110 & 11,32 & & 2,91 & 35,25 & 143,93 & 12.990 & 84,61 \\
\hline 5,069 & 210,490 & 66,97 & 320,40 & 3,9290 & 1258,85 & 191,88 & 17,360 & 84,76 \\
\hline 5,069 & 259,080 & 1313,28 & 320,40 & 4,8240 & 1545,61 & 232,33 & 21,190 & 84,97 \\
\hline
\end{tabular}

Table 2 Measured efficiency as function of output load

Comparison between measured and calculated loss:

Figure 9 compares the measured efficiency with the calculated. The calculation shows an efficiency about $2 \%$ lower than the measured. It is supposed that the difference lies in the use of worst case loss calculations for core losses, leakage inductance and paracitic capacitances. But in any way the calculated and measured data shows a very fine accordance even when considering the extreme low power levels.

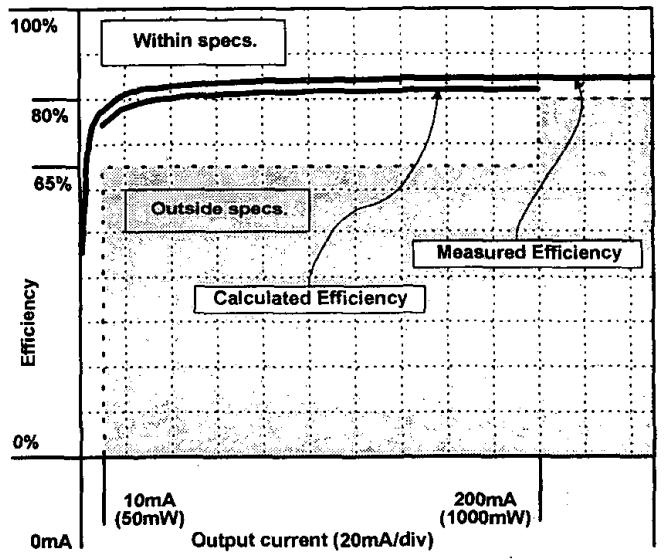

Figure 9 Comparison between calculated efficiency and measured efficiency, upper curve is measured efficiency

All efficiency measurements complies to a converter input voltage of $320 \mathrm{VDC}$ and an output voltage of $5 V_{D C}$. When the efficiency is measured at $230 V_{A C}$ it might be up to $0.4 \%$ lower. Please remark that the final efficiency figures, which are stated in the conclusion is the ones with the worst case measurement uncertainty subtracted and the above mentioned loss due to rippel on the link capacitor. All DC-measurement are made with HP-34401A Multimeters in 4-wire configuration. 
Table 3 shows the measured efficiency sensibility for various input voltage levels.

As it can be seen the efficiency is only changing by $2 \%$ when the input voltage is changed in the range from $75 \mathrm{VDC}$ and up to $450 \mathrm{VDC}$. This measurement documents that the efficiency only will be slightly affected when the input ripple voltage is very large.

\begin{tabular}{|c|c|c|c|c|c|c|c|}
\hline $\begin{array}{l}U_{0} \\
v\end{array}$ & $\begin{array}{c}10 \\
\mathrm{~mA}\end{array}$ & $\begin{array}{l}\mathrm{Po} \\
\mathrm{mW}\end{array}$ & $\begin{array}{c}\mathrm{U}_{\mathrm{iN}} \\
\mathrm{V}\end{array}$ & $\underset{\mathbf{m A}}{\mathrm{I}_{\mathbf{W}}}$ & $\begin{array}{c}P_{D \mathbb{N}} \\
\mathrm{mWW}\end{array}$ & $\begin{array}{c}\mathrm{fsw} \\
\mathrm{cyc} / \mathrm{s}\end{array}$ & $\begin{array}{l}\eta \\
\%\end{array}$ \\
\hline 5.069 & 605 & 56,52 & 75,07 & 4,182 & 13,97 & 5,917 & 81.70 \\
\hline 5,069 & 50,605 & 256,52 & 100,31 & 1113 & 312,27 & 5,435 & 82,15 \\
\hline 5,069 & 50,605 & 256,52 & 125,95 & 2,463 & 310,21 & 5,291 & 82,69 \\
\hline 5,069 & 50,605 & 256,52 & 150,31 & 2,055 & 308,89 & 5,102 & 83,05 \\
\hline 5.069 & 50,605 & 256,52 & 175,37 & 1,754 & 307,60 & 4,950 & 83,39 \\
\hline 5,069 & 50,605 & 256,52 & 200,40 & 1,532 & 307,01 & 4,785 & 83,55 \\
\hline 5,069 & 50,603 & 256,51 & 225,40 & 1,361 & 306,77 & 4,675 & 83,62 \\
\hline 5,069 & 50,603 & 256,51 & 250,10 & 1,225 & 306,37 & 4,525 & 83,72 \\
\hline 5,069 & 50,603 & 256,51 & 275,80 & 1,111 & 306,41 & 4,405 & 83,71 \\
\hline 5,069 & 50,603 & 256,51 & 300,10 & 1,022 & 306,70 & 4,292 & 83,63 \\
\hline 5,069 & 50,603 & 256,51 & 325,80 & 0,943 & 307,23 & 4,184 & 83,49 \\
\hline 5,069 & 50,603 & 256,51 & 350,25 & 0,879 & 307,87 & 4,082 & 83,32 \\
\hline 5,069 & 50,603 & 256,51 & 375,54 & 0.821 & & 4,000 & 83,20 \\
\hline 5,069 & 50,603 & 256.51 & 400,13 & & & 3,876 & 82,93 \\
\hline 5,069 & 50,603 & 256,51 & 425,50 & 0,731 & 310 & 3,802 & 82,52 \\
\hline 5,069 & 50,603 & 256,51 & $\overline{450,16}$ & 0,695 & 312,86 & 3.717 & 81,99 \\
\hline
\end{tabular}

Table 3 Measured efficiency as function of DC-link voltage

Figure 10 Compares the measured efficiency and calculated efficiency as a function of the input voltage. The upper curve is the measured one. And as the previous comparison there is a very good accordance between calculated result and measured results.

The up to $2 \%$ difference in efficiency may be caused by loss differences in the transformer, the use of too pessimistic component values and model divergence.

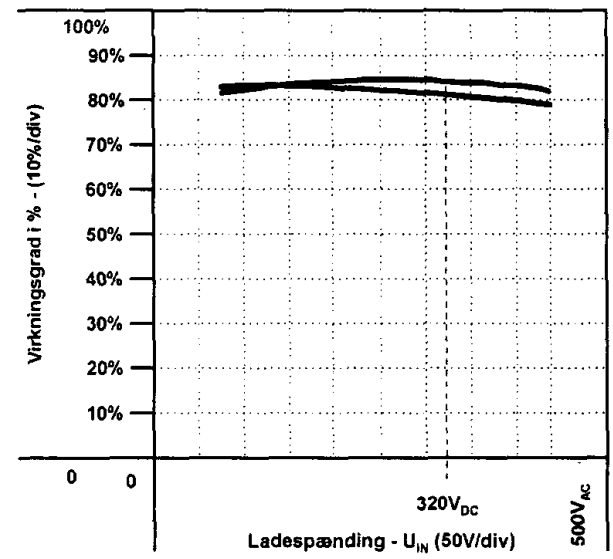

Figure 10 Comparison between calculated and measured efficiency as a function input voltage.
The final APDM based standby converter:

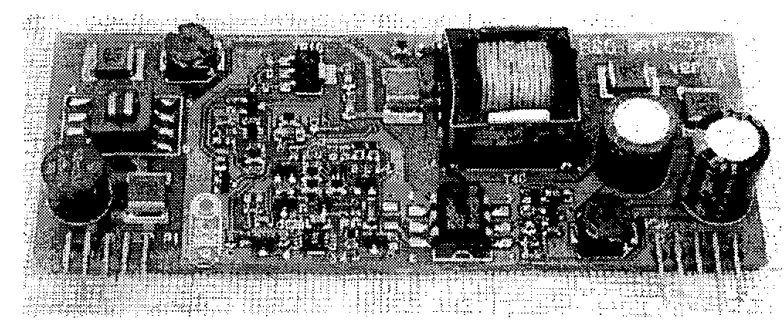

Figure 11 Picture of manufactured SPS-test module.

\section{CONCLUSION}

The final and fully functional design demonstrates an efficiency which reaches $76 \%$ at $50 \mathrm{~mW}$ load and $83 \%$ at $1000 \mathrm{~mW}$ load. The volumen of the shown test module is appoxemately $12 \mathrm{~cm}^{3}$. The power supply demonstrates the expected high ripple rejection which allows a very small primary link capacitor. It is also demonstrated that the input voltage range can be extended to cover universal mains range simply by adding an $4.7 \mu \mathrm{F} / 385 \mathrm{~V}$ capacitor. It is succeded to design the control circuit in a way so it can easily be implemented by using cheap off-the-shelf components. Furthermore the control circuit is designed in a way, which facilitates a later custom IC-realization.

\section{REFERENCES}

1. N. Nielsen, "Standby Power Supply - En energieffektiv netdreven ultra laveffekts spaendingsforsyning", Ph.D. Thesis, DTU, DK-2800 Lyngby, Denmark, 31 May 2000, 244 pages. (In Danish)

2. Technical University of Denmark - DTU, Anker Engelundsvej 1, DK-2800 Lyngby, Denmark., (http://www.dtu.dk).

3. Danish Energy Agency, Amaliegade 44, DK-1256 Copenhagen - K, (http://www.ens.dk)

4. The cooperative parters are: 1.) Bang \& Olufsen, Peter Bangs Vej 15, DK-7600 Struer, Denmark, (http://www.bangolufsen.dk/). 2.) Dantrafo A/S, Islandsvej 28, DK-8700 Horsens, Denmark, (http://www.dantrafo.dk). 3.) Electrolux Hot Tech-Center, Sjaellandsgade 2, DK-7000 Fredericia, Denmaek, (http://www.electrolux.dk).

5. N. Nielsen, "Topologi undersoegelse", DTU, DK-2800, Lyngby 19 January 1998, Denmark, 57 pages. (In Danish)

6. N. Nielsen, "Reference maalinger paa konventionelle $50 \mathrm{~Hz}$ SPS topologier", DTU, DK-2800 Lyngby, 15 July 1999, Denmark, 114 pages. (In Danish)

7. N. Nielsen, "Reference maalinger paa SPS egnede $50 \mathrm{~Hz}$ transformere", DTU, DK-2800 Lyngby, 18 April 1999 Denmark, 125 pages. (In Danish)

8. N. Nielsen, "State of the art undersoegelse", DTU, DK-2800 Lyngby, 19 January 1998, Denmark, 54 pages. (In Danish)

9. N. Nielsen, "Preliminary diagrams and a functional description of SPS based on the APDM operation", DTU, DK-2800 Lyngby, 15 June, 1999, Denmark, 27 pages. 